\title{
A Pragmatic Semeiotic Perspective on the Concept of Information Need and Its Relevance for Knowledge Organization
}

\author{
Martin Thellefsen*, Torkild Thellefsen**, and Bent Sørensen*** \\ *University of Copenhagen, Royal School of Library and Information Science, \\ Fredrik Bajers Vej 7K 9220 Aalborg Øst, Denmark, <Cpx896@iva.ku.dk> \\ **University of Copenhagen, Royal School of Library and Information Science, \\ Fredrik Bajers Vej 7K, 9220 Aalborg Øst, Denmark, <pxd739@iva.ku.dk> \\ ***<coeno@gmail.com>
}

Martin Thellefsen, MA and PhD in library and information science. Associate professor at the University of Copenhagen, Royal School of Library and Information Science, Fredrik Bajers Vej 7K 9220 Aalborg Øst.

Torkild Thellefsen, MA in library and information science, $\mathrm{PhD}$ in information architecture and holds the degree of Dr. Merc. in cognitive branding. Associate professor at the University of Copenhagen, Royal School of Library and Information Science, Fredrik Bajers Vej 7K, 9220 Aalborg Øst.

Bent Sørensen, MA in Arts \& Humanities. Independent scholar.

Thellefsen, Martin, Thellefsen, Torkild, and Sørensen, Bent. A Pragmatic Semeiotic Perspective on the Concept of Information Need and Its Relevance for Knowledge Organization. Knowledge Organization. 40(4), 213-224. 53 references.

ABSTRACT: The organization of information and the process of seeking information are fundamental activities, and thus fields of study, related to library and information science (LIS). Both endeavors are pragmatic in the sense that the ideas of information seeking behavior and the process of organizing information relates to some ideas of how users tend to behave when information is needed in order to fulfill a task of some kind. An important difference is, however, that information systems are primarily driven by principles of semantic structure, whereas users are driven by genuine information needs. Knowledge organization (KO), which is considered a subfield within LIS, has a particular focus on the organization of semantic units, and their relations (Hiørland 2008; Hodge 2000; Thellefsen 2010), however, it is our impression that the users information need, even though acknowledged, often is neglected or only mentioned en passant. The concept of information need is a core concept in LIS, and is, in particular, a core concept within the subfield of information retrieval (IR) that describes the state of uncertainty or anomalous knowledge state that precedes a user's information seeking behavior. Information need is, however, an intricate concept, and is only addressed in the LIS literature as some kind of elusive cognitive state. One may ask 'is an information need always individual or personal, and under what circumstances?' The present paper argues that the concept of information need may profit from a pragmatic and semeiotic perspective, which also may prove fruitful for $\mathrm{KO}$. The paper thus discusses the concept of information need through three premises that is formulated based in Peirce's pragmatic semeiotic: 1) as the intricate relation between believe and doubt, 2) as a pragmatic process of clarification, and 3) as an activity of cognition taking place within a universe of discourse. The paper is rounded by a discussion of how this semeiotic analysis can be useful for KO.

Received 12 December 2013; Revised 26 April 2013; Accepted 30 April 2013
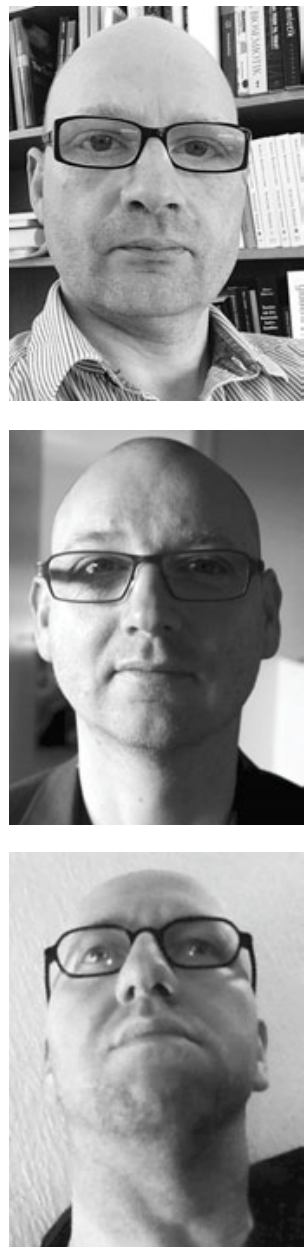

Nothing can possibly be learned from an experiment that turns out just as was anticipated. It is by surprises that experience teaches all she deigns to teach us.-Charles S. Peirce ${ }^{1}$ 


\subsection{Introduction}

"Knowledge organization systems are used to organize materials for the purpose of retrieval and to manage a collection. A KOS serves as a bridge between the user's information need and the material in the collection."-Hodge

The metaphor of $\mathrm{KO}$ as a 'bridge' or 'bridging the gap' is known from the IR literature, in particular in the terms of Dervin's sense-making metaphor (Ellis 1990). KOS (knowledge organization systems), thus, are means to an end, tools that serve its purpose in aiding users seeking information.

The general conception of KO means bringing knowledge into some kind of order or structure. However, the knowledge considered for organization is that which is materialized in different kinds of media, and therefore knowledge organization is more precisely defined as the research area within information science that has a particular interest in the organization of recorded knowledge, which, in principle, is the same as information. More precisely, though, knowledge organization is really focused on types of systems (KOS), modes of representation, purpose of information architecture, interaction design, etc. In fact, research in knowledge organization, with few exceptions ${ }^{2}$ and despite its terminology, is very little concerned with knowledge as phenomenon ${ }^{3}$, how it is communicated, and interpreted within communities, but contrarily mostly concerned with the general and often nomothetic features of information and information systems, as formulated by, for example, Hodge (2000) and Lykke Nielsen (2002). Furthermore, textbooks used at the Royal School of Library and Information Science that introduce students of LIS to the field of KO support this assumption (e.g., Case 2007; Chowdhury and Chowdhury 2007; Göker and Davis 2009; Hagler 1997; Hodge 2000; Rowley and Hartley 2007). Consequently, evaluation of KOS tends to be more concerned with how well objects of knowledge are represented within a particular semantic structure (a classification scheme or a thesaurus) and bibliographical control, than with how well the KOS in principle acts as sender in a communication process. ${ }^{4}$ In fact, few communication studies have been conducted within LIS and KO in particular. ${ }^{5}$ As such, the basic function and purpose of KOS can be summarized as:

1) facilitating information retrieval (IR-function);

2) providing information about documents (document information function-document surrogate (representation); and

3) providing shelf arrangements (ordering function) (Broughton et al. 2005).
In his 1991 book Information and Information Systems, Buckland provides for a deeper analysis of the concept of information in relation to information systems. Buckland points out, that the concept of information is ambiguous and problematic in nature. The major insight provided by Buckland is that information as such, may relate to things, to processes, and to knowledge.

In the terms of Buckland (1991), the aspects of KOS summarized by Broughton et al. (2005) all relate to the information as thing' paradigm. Following this line of thought, information is related to physical items, or immanent qualities of objects, e.g., documents. However, as pointed out by Buckland: "...we are unable to say confidently of anything that it could not be information" (Buckland 1991, 50, italics in original), leading to the rather pessimistic conclusion: "if anything is, or might be, informative, then everything is, or might well be, information. In that case, calling something information does little or nothing to define it. If everything is information then being information is nothing special." Consequently, in order for information to be more than everything or nothing, the concept should be qualified by perspective, context, and use. Accordingly, Buckland also discusses the role of information in relation to knowledge and the process of becoming known.

Information in relation to knowledge and becoming known changes the perception of information, because knowledge and becoming known involve an idea of communication, i.e., a sender and a receiver. In this respect, searching a database also involves a 'quasi' communicative effort, e.g., being able to formulate a query, and successively, evaluation of the search result. Evaluation, use, consumption, interaction, communication, and meaning-making add complexity to our sense of information and the object as such becomes secondary. Consequently, investigating KOS, disregarding the interpretive and intangible side of information and information interaction, provides us with a barren, rudimentary, and theoretically naïve understanding of information, a similar point also made by Brier (2006a, 2006b), Frohmann (2004), Hjørland (2002b, 2003), and Thellefsen et al. (2003).

Several LIS scholars, thus, have addressed the dynamic and qualitative aspects of information and argued about the importance of including users and their interactive behavior in information seeking and IR, for example, particularly in terms of 'sense making' as suggested by Dervin (1998) and learning and seeking meaning in the information seeking process (ISP) as formulated by Kuhlthau (1991, 2004).

The cognitive view relates the users' uncertainty and thus motivation of information retrieval to the $\mathrm{ASK}^{6}$ hypothesis (Belkin, Oddy, and Brooks 1982) or to a "knowledge gap," which, in some cases, address the distance be- 
M. Thellefsen, T. Thellefsen, B. Sørensen. A Pragmatic Semeiotic Perspective on the Concept of Information Need...

tween the user seeking information and the information system representing information. In other cases, the knowledge gap addresses what the user knows about a problem or a topic and what the user needs to know in order to solve the problem (Kuhlthau 1991). However the process of becoming aware of an ASK, a knowledge gap, etc., how is it actually recognized? How does a user know what to look for if an information need, in terms of ASK, is inarticulate or a vague feeling of uneasiness, and when does the user know that the ASK is fulfilled? Consequently, we need to reflect on the process that motivates a conscious but inarticulate state of information need, and we furthermore need to reflect on how user satisfaction is assessed.

The conception of information as a need also has some connotations worth mentioning. By considering information as something needed or desired, following a path of fulfillment, the parallel to other kinds of biological needs seems obvious. However, is an information needparticularly as described within the LIS literature, as an ASK - really similar to a biological need, e.g., for food, shelter, sex?, Brier (2004) argues that LIS information theories are dominated by the information processing paradigm that describes information, information need, and thus information processed in terms of rationalist epistemology. An information need is thus determined as rational function of a cognitive state (including previous knowledge/experience), a work task, interest, and domain (Ingwersen 1996). However, as pointed out by Brier (2004), the cognitive view has its focus on users' information seeking behavior, it assumes that the social plays a role in determination of 'aboutness' or relevance of documents; however, it fails to explain how the social or the domain actually plays an active role in the information seeking process, simply because the research interest of the cognitive view is restricted to individual users' information behavior in front of a document-mediating system. Consequently, how can an information theory that only assumes a social bias, that ultimately explains information in terms of bits and bytes, claim to be a comprehensible theoretical framework for LIS, when such important aspects as mind, intentionality, language, and meaning involving selective perception are excluded from the equation? Consequently, an information need as formulated in Belkin's ASK hypothesis, which still is the predominant understanding of information need within LIS, cannot be similar to a biological need. Human life does not depend on information seeking!

Frohmann (1992) has similar doubts and formulates his critique of what he considers the naturalist conception of information formulated by Brookes, (cf. Brookes $1975,1980 \mathrm{a}, 1980 \mathrm{~b})$, one of the founding fathers of the cognitive view, as follows (Frohman 1992, 369):
Throughout, information is situated within a discourse of natural processes, whether 'transmission' of 'neural electrical pulses,' 'biochemical transmissions that occur in the cell' [17, p. 118], or 'ranges of physical signals' impinging upon sensory organs. The evolutionary series begins with 'physical processes,' not excluding 'the absorption of energy and nutrientsn' The absorption of food by 'simple unicellular creatures' becomes a primitive information process-'the basic Shannon information system limited to two possible discrete signals' [17, p. 120], i.e. food and nonfood. When 'eventually man emerged from among the higher animals' [17, p. 121], the natural-scientific metaphors continue; human understanding is conceived as a higher-order 'information process,' a 'cognitive interpretation' of 'signals' by a 'cortex' [17, p. 118; 18, p. 46]. The apogee and final telos of this naturalistic movement is the computer metaphorised as an 'exosomatic brain' [17, p. 122], and presented as a parallel, in the cognitive realm, to such previously enumerated extensions of human sensory faculties as the microscope and the telescope [17, p. 122; 18, p. 47], themselves spoken of as products of a natural evolution of information processes. Indeed, evolution itself is regarded as 'more effective informationgathering, processing and exploiting' [17, p. 121]. ${ }^{7}$

In this context, life itself is reduced to information processing. Human agents consume information as well as food and energy. And information is in principle objects that may be decomposed, handled, consumed, etc. Information defined as a commodity, however, does not account for how information becomes meaningful and how it is transformed into knowledge.

Information is a complex concept, and we will not provide for a philosophical analysis of the information concept in this paper. We will, however, restrict our use and understanding of information to the context of information seeking and knowledge organization. We are fully aware, though, that the philosophical underpinnings of the information concept have important consequences for how we may speak of and understand information. In our view, we believe that information needs within any information-seeking context always should be considered means to an end, and never the goal itself. Information is the means, knowledge the goal. This view is shared by other LIS scholars (e.g., Andersen 2004; Wilson 1968) who have a particular focus on documents as textual means, and others (e.g., Hjørland 1997; Hjørland and Albrechtsen 1995) who consider knowledge organization and information retrieval as discursive and purposeful. 
This paper is sympathetic with Buckland's understanding and critical view of 'the information as thing' paradigm and investigates information in relation to knowledge, or, more precisely, the process of information becoming known. We do not disregard the importance of information systems. Information systems are, on the contrary, regarded as the required structure/architecture that organizes physical items of recorded knowledge. However, by, on one hand, taking the perspective of information as the 'means' for 'knowing,' hereby defining structure/architecture as the fundamental 'grammar' of representation (that affects a user to act in a certain purposeful yet limited manner), and, on the other hand, taking the cognitive effect motivated by representations as a determination of goals, it may be possible to rethink the relations between representation and cognition (information need) in information systems interaction in terms of a dynamical communicative process.

\subsection{Stating the scope}

This paper formulates a theoretical framework that unites the interrelated functions of representation, communication, and meaning. As argued above, KOS are systems of representation, that more or less sophisticatedly organize semantic units and their relations; however, KOS go beyond self-referential formal structures, because KOS affect minds in terms of relevance assessment, in terms of behavior (e.g., how to proceed the interactive process of information seeking), in terms of acquisition of information sources, etc.

Furthermore, this dyadic relation between representation and conduct is constrained further by contextual circumstances, both by the architecture of the system itself but indeed also by the knowledge possessed by the user of KOS. KOS are therefore considered systems that represent semantic units and their relations that reach beyond the formal structure and internal order by motivating cognitive processes in human minds, that again are delimited by certain contextual barriers and preferences.

Addressing the question about information need and knowledge structure from a pragmatic and semeiotic perspective has some advantages that might be useful in LIS. Firstly, by seeing information systems and knowledge structures as fundamentally different semeiotic structures, we are able to establish a clear distinction between information and knowledge. Secondly, by arguing that information seeking and retrieval fundamentally are pragmatic in nature, we are able to address the dynamical nature of information seeking activity - that knowledge structures are flexible and accommodative, and that a user's interaction with an information system essentially is a communicative process of making ideas clear. And thirdly, un- derstanding the information need from a semeiotic viewpoint gives us a better understanding of the cognitive processes going on when an information need is identified and how, when and why it is fulfilled. ${ }^{8}$

Consequently, in order to make our conception of information need intelligible, we must base our thinking about information need on the pragmatic premise that knowledge is cultivated by a continuous dialectic condition between the concepts of doubt and belief. Where there is doubt, there is encouragement to investigate; where there is belief, there is encouragement to critically scrutiny. As we will touch upon later in the paper, doubt, according to Peirce, is an existential condition not only for reasoning but for life itself-for evolution. It cannot be compared with the IR concept of 'uncertainty' since this concept is limited to information seeking.

Seeking the solution to a problem may thus follow the path of testing hypotheses and different ideas and models for explication and, in the end, enabling the user to select the best possible explanation, that follows the path of reasoning based on clear premises; this is in accordance with Peirce's pragmatic view as he poetically expresses it in the Harvard Lectures on Pragmatism (1903, CP 5.51): "nothing can possibly be learned from an experiment that turns out just as was anticipated. It is by surprises that experience teaches all she deigns to teach us." The paper subsequently sees the concept of information need through the following premises:

Premise 1: An information need is basically a state of doubt caused by information; a fullfilled information need may when processed by cognition turn into knowledge.

Premise 2: Information needs arise in relation to work tasks or problem situations.

Premise 3: The fulfillment of information needs is a creation of belief relative to a universe of discourse and collateral experience.

Let us now take a look at these three premises one by one.

\subsection{What is an information need- and how does it emerge?}

The concept of information need has been widely discussed within the literature of LIS, especially in research related to information retrieval (IR) (Bates 2002; Belkin et al. 1982; Borlund and Ingwersen 1997; Dervin and Nilan 1986; Ingwersen 1996; Kuhlthau 1991, 2004; Taylor 1968). Fundamentally the approaches to information need can be divided into two main categories: 1) information need as an emerging cognitive process that follows different stages of development; and 2) information need as a state of 
M. Thellefsen, T. Thellefsen, B. Sørensen. A Pragmatic Semeiotic Perspective on the Concept of Information Need...

anomaly. Both approaches are concerned with reducing uncertainty. Accordingly, the first understanding tends to investigate the cognitive processes that take place when a user approaches an information desk (cf. Taylor 1968), or the process of making sense of a phenomenon, e.g., in terms of 'bridging a knowledge gap' (Dervin 1998); in particular, Kuhlthau (2004) has stressed the importance of emotions in the process of reducing the knowledge gap. The second category investigates the concept of information need in terms of a state of uncertainty but within an IR setting. The major difference seems to be between seeking and IR, the former may lead to an ASK addressed within an IR setting.

However, as we will demonstrate the concept of information need may profit from an analysis anchored in pragmatic thinking and semeiotic analysis. Peircean semeiotics constitutes a theory of reasoning (critic), ${ }^{9}$ and Peirce's pragmatic maxim is a central part of inquiry (methodeutic) (CP 2.191). "But pragmatism does not undertake to say in what the meanings of all signs consist, but merely to lay down a method of determining the meanings of intellectual concepts, that is, of those upon which reasonings may turn" (CP 5.8). It is important to stress at this point that, for Peirce, the pragmatic maxim is a general method for ascertaining the meaning of an intellectual conception by considering its conceivable consequences, which may follow logically from the conception. Peirce formulates the pragmatic maxim in the following way: "Consider what effects, that might conceivably have practical bearings, we conceive the object of our conception to have. Then, our conception of these effects is the whole of our conception of the object" (CP 5.402). Furthermore, for Peirce, the pragmatic maxim is connected to his concept of truth, where truth is that upon which reasoning in the long run may turn; or put in another way, the maxim concerns those signs that are essential to the pursuit of truth by means of inquiry (See Forster 2011, 66).

\subsection{Ad Premise 1}

Peirce's pragmatic maxim thus implies a telos, a direction of reasoning, and is consequently concerned with consequences rather than solutions. Following Peirce`s line of thought, the concept of information need relates to reasoning. An information need arises on account of a problem situation or a phenomenon that cannot be explained by means of current knowledge. Peirce (1992, vol. II, p. 287) sums up this situation nicely:

Its occasion is a surprise. That is, some belief, active or passive, formulated or unformulated, has just been broken up. It may be in real experience or it may equally be in pure mathematics, which has its marvels, as nature has. The mind seeks to bring the facts, as modified by the new discovery, into order; that is, to form a general conception embracing them.

Therefore sources of information are consulted in order to provide a satisfying answer. The awareness of the insufficiency of current knowledge is itself pragmatic in nature, because reasoning about what is known, clarifying what is unknown is itself on the path of future enquiry. Consequently, we understand the information need as a state of doubt caused by information, and it ceases when belief is attained, as Peirce writes in his famous article "How to Make Our Ideas Clear" (CP 5.394):

The action of thought is excited by the irritation of doubt, and ceases when belief is attained; so that the production of belief is the sole function of thought. All these words, however, are too strong for my purpose. It is as if I had described the phenomena as they appear under a mental microscope. Doubt and Belief, as the words are commonly employed, relate to religious or other grave discussions. But here I use them to designate the starting of any question, no matter how small or how great, and the resolution of it.

In Thellefsen et al. (2013) and Sørensen et al. (2013), we define our semeiotic understanding of information as being part of a trichotomy consisting of emotion, information, and knowledge (we use knowledge synonymously with cognition). In these papers, we analyze the meaning creation process and conclude that three elements seem to make up the process of meaning creation: emotion, information, and cognition. They also seem to be understandable within Peirce's theory of consciousness consisting of primisense (emotion), altersense (information), and medisense (cognition) (CP 7.551). Consequently, the bringing of sub-consciousness to self-consciousness is similar to the process of meaning creation or semeiosis. When relating the concept of information need to the meaning creation process, we can say that the information need is caused by information (altersense); it causes doubt (an emotional state) in the mind. ${ }^{10}$ Doubt is, in itself, not a cognitive state of mind but a privation of belief (medisense) (cf. CP 5.471). Only when the doubt ceases and belief is attained, is knowledge (medisense) created; consequently, the meaning creation process involves information, which may cause further need for information (an information need is created) in order to settle the doubt. It may be important to stress that, in our view, information does not always cause doubt. Information can also confirm hypotheses. However, when it does cause doubt, it creates an information need. In the previous quotation, Peirce points out this ongoing struggle between be- 
lief and doubt, "But here I use them [doubt and belief] to designate the starting of any question, no matter how small or how great, and the resolution of it" (CP 5.394). Consequently, it is erroneous to believe that, for every information need identified, there is some particular information that can fulfill the need. An information need often causes several other information needs to arise, often leaving belief in the hands of doubt. This suggests an ongoing process of settling doubt. This process is identical to Peirce's concept of infinite semeiosis.

Summing up with Peirce (CP 5.416-417), knowledge:

is not a momentary mode of consciousness; it is a habit of mind essentially enduring for some time, and mostly (at least) unconscious; and like other habits, it is (until it meets with some surprise [information] that begins its dissolution) perfectly selfsatisfied. Doubt [caused by information] is of an altogether contrary genus. It is not a habit, but the privation of a habit. Now a privation of a habit, in order to be anything at all, must be a condition of erratic activity that in some way must get superseded by a habit.

The information need, in order to be more than an anomalous state of knowledge, ${ }^{11}$ must be transformed into reasonable lines of consequences that demand further investigations, in order to provide for the best and most reasonable answer given the beforehand knowledge. The information need itself, however, is also an emotional effect that is motivated by the particular situation caused by information that has affected our state of habit. Consequently, information need relates to emotion, information relates to matter, ${ }^{12}$ and knowledge relates to the knowing mind.

\subsection{Ad Premise 2}

An information need arises in relation to a work task, a problem situation, a hypothesis, or some kind of curiosity. The information need of a scientist arises within a process of research, where the ability to explain phenomena by means of acknowledged theories following accepted methods and ethics of research is critical. Other kinds of information need may arise based in everyday conduct, thus seeking ad hoc information, or facts. Consequently, we should distinguish between information needs that are attentive to known facts, objects, phenomena, etc., and information needs that inquire into the unknown.

A person who misses his bus needs to know when the next bus leaves. In order to get his information need fulfilled, he searches the timetable for the bus. This is straightforward. You need information, you seek it and get an answer, and the information need is fulfilled.
A researcher who has made observations (observations being information) that bring him to doubt his theory needs information that can either make the doubt cease, causing belief to be attained, or strengthen the doubt. In this latter case, the researcher has an information need or a knowledge gap, both of which are caused by information; he is in a state of doubt (an emotional state). It is important to stress that, in our view, information is defined in terms of the trichotomy: ego, non-ego, and cognition, non-ego being whatever may be outside ego; only cognition can bridge the gap between ego and non-ego. Taking this a little bit further, this trichotomy is related to Peirce's phaneroscopic categories of Firstness (ego), Secondness (non-ego), and Thirdness (cognition) and also to the aforementioned consciousness trichotomy: qualisense, altersense, and medisense. This involves that information is whatever lies outside ego, information is reality, and it is only when interpreted that information can become knowledge, and, since Peirce's first cotary proposition reads: nibil est in intellectu, quod non prius fuerit in sense, no knowledge can arise without information, no doubt nor information need can arise without information. Not even a person's reflection on his or her own state of knowledge can be initiated without information, since something has to cause feeling, action, or reasoning, this something is information.

However, at this point, the researcher may not know how to overcome his doubt, since he does not know what kind of information can reestablish his belief. As Peirce writes in "How to Make Our Ideas Clear": "The irritation of doubt causes a struggle to attain a state of belief. I shall term this struggle Inquiry" (CP 5.370-375). We believe that most research is often performed at the edge of doubt, remembering, for example, Peirce's concept of fallibilism and Popper's theory of falsificationism. It is the struggle between doubt and belief that causes science to progress. Let us sum up the relation between doubt, belief, and information need using the following figure (1):

\section{Cognition}

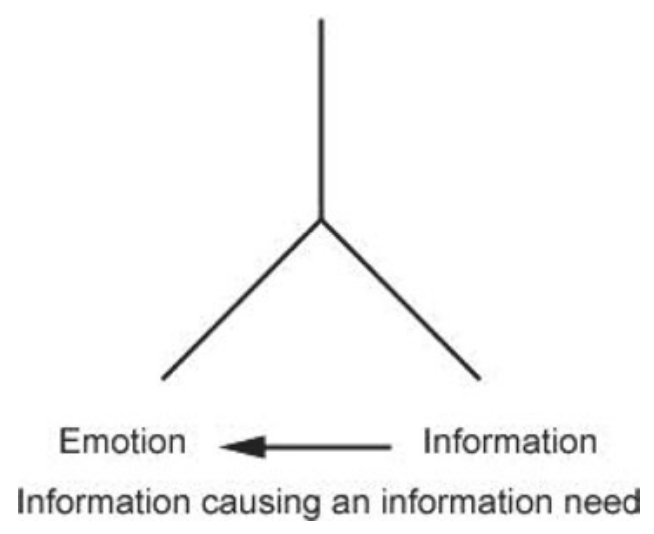

Figure 1. The creation of an information need. 
M. Thellefsen, T. Thellefsen, B. Sørensen. A Pragmatic Semeiotic Perspective on the Concept of Information Need...

Perceiving information always causes emotional effects. An information need is related to a state of doubt, and the state of doubt is always caused by information. In the case of the researcher, he makes observations (he observes information), and this information causes emotions in him. The particular observations bring doubt to his mind, causing an information need. The irritation of doubt makes him wonder (cognition) if his theory is correct, and if he needs to adjust his theory. This is a continuous and dynamic process.

\subsection{Ad Premise 3}

The universe of discourse is defined as the socially framed or situated context wherein the information seeking activity takes place. The user's problem space or work task situation is anchored in a certain context that provides meaning, scope, and purpose to the information seeking behavior. Deliberate information seeking is never random, but, as argued above, purposeful and goal directed. Understanding the context of deliberate reasoning that gives rise to the formulation of a particular information need is thus imperative.

Inspired by Peirce's pragmaticism, we place the concept of information need as something internal to a mind (doubt). An information need is triggered by the external world, which is information. Figure 2 provides a semeiotic model of communication. The concept of significance-effect is considered an effect of meaning, which is

\section{Cominterpretant}

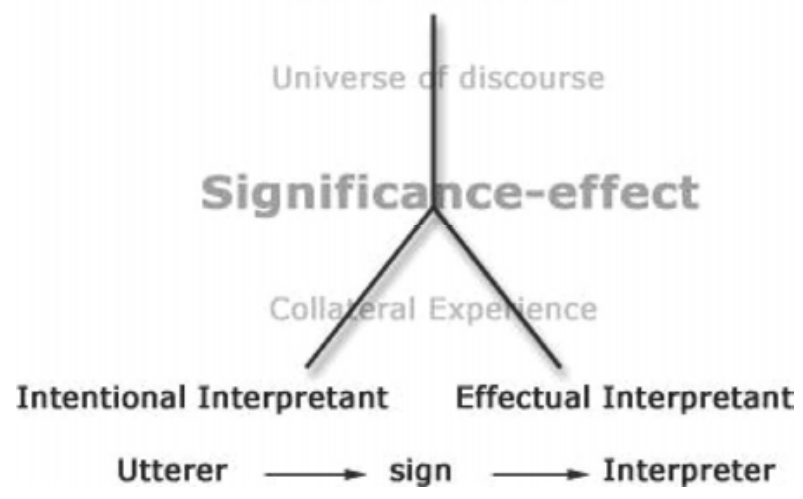

Figure 2. The Dynacom model (Thellefsen et al. 2011) and (Thellefsen et al. 2006)

relative to collateral experience and a universe of discourse. Consequently, the meaning of a sign, for example, an observation of a phenomenon, an incident, or even an idea, is relative to what is already known by the perceiving mind, and to a universe of discourse. Originally, the Dynacom model (Thellefsen, et al. 2006) was considered a communication model of separate entities: the utterer, a mind or quasi mind, and the interpreter. However the
Dynacom model may also illustrate self-reflection, or a process of thinking, because, as Peirce argued, all thinking is dialogic in form, a dialogue between the self and a future critical self (see CP 6.338). Hence, an idea or a hypothesis may as well be considered an intentional interpretant, and the significance-effect thus depends on the known premises of the hypothesis, following the lines of deliberate reasoning (abduction, deduction, induction). Consequently, the concept of information need may to be considered a particular kind of significance-effect.

Let us exemplify this by using the following thought example: a Bach scholar searches a bibliographic database for a particular score by Johan Sebastian Bach (his information need). This score is important to him since he needs it to be able to prove a scientific point; a scholarly question has brought doubt to his mind. He is used to searching the particular database and he is capable of identifying the relevant findings - he possesses collateral experience. He makes the search using the search phrase "j.s bach \& suites for harpsichord." This results in-let's say-100 relevant matches where two are highly relevant. Let us try to analyze this example using the Dynacom model.

The Bach scholar writes a query-this makes him the utterer; he utters information; this utterance is endowed with intentionality, which is an intentional interpretant. The system receives the query and reacts upon the query-this makes the system a quasi-interpreter; it is effected by the intention of the query and therefore represents an effectual interpretant. It is quasi, since the system is not able to react in other ways than it is programmed to; but still it is an interpreter since it translates the query into a given search result. The real interpreter is the Bach scholar since he uses the user interface as a medium in his dialogue.

So the Bach scholar is both the utterer and the interpreter. This seems analogous to someone writing on a piece of paper-this is also a dialogue between the writer and his future self, but, in this case, he has more control over what he writes, his thoughts are more identical to his writings on the paper. The difference between the writing on the computer and the writing on the paper is that the paper does not transform the written word (e.g., by means of search algorithms that may provide for best match ranking) in a way hidden to the writer, whereas the text written in the query field definitely is altered when processed by the computer, hence, the meaning becomes altered. This is also the case when communicating to another person or a group of persons. The utterance embedded with a certain intentionality may be completely misinterpreted by the interpreter. The more collateral experience shared between the utterer and the interpreter the greater the chance is for a correct interpretation (the cominterpretant). 
In the case with the Bach scholar, it is a dialogue between him and his future self, mediated by the interface of the bibliographic database; but when he sends the query, he loses control of it. He does not know how his query is being processed. However, this may occur to him when he gets the result of the search, which causes an effectual interpretant in the utterer. In order for the Bach scholar to have a successful experience, the database must return documents that match his information need. But the assessment of relevance of documents is, of course, based on the amount of collateral experience the Bach scholar possesses about his information need. The more collateral knowledge the Bach scholar possesses about his information need, the more likely will he be capable of determining the relevance of the search result.

\subsection{Concluding thoughts-a semeiotic inspired concept of information need}

Information science, in particular the fields concerned with organization and retrieval of information, struggle with a fragmented view of the information processes connected to the areas of the information system itself, the human agents interacting with the system, and the community that frames information behavior of the individual users. We believe that this fragmentation stems from a tradition of unclear thinking within LIS about key concepts as demonstrated in this paper, the concepts of information need, and the ASK hypothesis are unclearly described, and their ontological and epistemological status is hidden behind elusive metaphors.

The pragmatic and semeiotic line of thought, however, is not a bird's eye and neutral perspective. It is, rather, as formulated in this particular context, a method for reasoning about the information processes connected to the information system, the conduct of human agents, and the community.

We have demonstrated that the pragmatic and semeiotic view takes into account that signs are signs of meaning; that users interpret signs, and use signs in their information seeking activity, simply because the signs carries meaning to the user. However, the meaning of signs and the ability of users to interpret the signs is relative to the individual level of collateral experience.

Based on this, let us try to define the concept of information need from our semeiotic perspective. The information need is related to a state of doubt. Maybe it would be more appropriate if LIS adopted this terminology, since information need has several terminological problems. First of all, needing information cannot be considered a need like biological needs. Secondly, we believe that information needs within any information seeking context always should be considered means to an end, and never as a goal itself. If the aforementioned researcher searches for information, it is not information per se that he is interested in, it is rather the knowledge it may bring him; consequently he has a knowledge need, not an information need. An information need is caused by information. As such the information need is an emotional state, a state of doubt. Only cognition can acknowledge the information need, and the mind will, if it is possible, try to overcome the irritation of doubt. In order to acknowledge the information need, collateral experience is necessary. We have to know something in order to be brought into doubt; this something is presupposed conditions including accepted theories, axioms, academic discussions, and networks of thoughts, in short collateral experience.

However, often when we interpret information, we ascribe intentionality to information; intentionality that is not in the information but may be connected with the particular information. Just think of occasions when we misinterpret information and interpret it in relation to our collateral experiences. It is often our own misinterpretation or wish for a particular interpretation that bring us into doubt. Below we give some examples on information without intentionality but where the interpreter adds directness to the information by interpreting the information.

Imagine a twig that is broken by the wind in a wood. The information comes in the form of a sound. The interpreter interprets the sound as someone following him. He possesses collateral knowledge about the sound of a breaking twig, maybe he recognized this situation from horror movies he saw in his youth. This causes many emotions: fear, nervousness, curiosity, but most of all doubt, since he questions his own hypothesis regarding the follower. The person in this example resides in doubt, he has an information need, he needs to know whether he is being followed or not, and, if he is, whether the follower is dangerous, and if he is ... and so on. Doubt brings forth a lot of questions or information needs that only can be fulfilled when the interpreter finds out that it was not a person breaking the twig. The interpreter is interested in removing the irritation of the doubt by attaining knowledge about who made the sound. It is not so much the fulfillment of the information need that is the important element, but knowledge about what made the particular noise.

The Bach researcher from before has put forth a bold hypothesis based on different kinds of observation. He is convinced that Bach wrote two St. Matthew passions, one that survived and another one that is lost. How has he made this hypothesis? Based on different important sources, he has come to the hypothesis. In order to prove the hypothesis, he needs further information about the life and whereabouts of Bach-does the researcher have an information need? He certainly is in doubt, since it is only a hypothesis that lacks the final proof. This doubt may never 
M. Thellefsen, T. Thellefsen, B. Sørensen. A Pragmatic Semeiotic Perspective on the Concept of Information Need...

be removed, since the researcher may never find the decisive proof. Here it is not about fulfilling an information need. Here, doubt or the information need is a catalyst for further research. The irritation of doubt causes a struggle to attain a state of belief; this struggle may be called inquiry. Summing up, we believe that the concept of information need within LIS needs some philosophical considerations and clarifications. As long as there is not a common understanding in LIS between information and knowledge, an information need could also be called a knowledge need. We advocate for using the concept of doubt instead of information need, since doubt is what the person experiences when needing some kind of information.

\subsection{The perspective for knowledge organization}

As was discussed in the beginning of this paper, knowledge organization, in particular in terms of KOS, deals with representation of information sources. Furthermore, KOS serves a purpose, namely enabling users to retrieve stored information (or recorded knowledge). Of course, we may differentiate between kinds of representation systems that provide for different levels of affordance to the user, but this is merely a matter of granularity. The primary function is the same, namely to represent information sources, and to express semantic relations in a controlled vocabulary or a classification scheme. Throughout this paper, we have argued that the concept of information need is intricate and based upon unclear theoretical foundations, and we have argued that the concept of information need, even though often neglected, is important in relation to knowledge organization and the development of KOS. How else would it be possible to develop useful information architectures if not information needs or user warrants were anticipated?

We have furthermore argued that the interactive process of information seeking resembles a process of communication (or rather quasi-communication), where the dynamical part is the person seeking information, that constantly modify requests and interprets search results according to a problem situation. We discussed this kind of communication as an act of self-communication, where the information system bounces off results based on search activity. ${ }^{13}$ As such, the information system plays an important role in this communication process, enabling the user to formulate and reformulate search requests based on previous search results. From the semeiotic perspective, the information system constitutes the formal structure of information, signs that guide the user toward information sources; however, the nature of modifying a request, judging search results relevant, and selecting the best suited sources is a matter of semeiosis and genuinely pragmatic. From this perspective, information seeking is a matter of clarification that involves collateral experience and a fundamental understanding of context (or in Peirce's own terms, a 'universe of discourse'). However, based on Peirce's pragmatic philosophy, we may also argue that information needs always are motivated by signs exterior to a mind, i.e., information needs are based in experience.

Following our line of thought, information systems should be developed based on a clear idea of being part of a process of communication. Therefore, information systems should be developed by including domain knowledge (collateral experience). They should continuously be revised according to the knowledge interests they serve, and development of KOS may profit from a more profound understanding of users information need and information seeking behavior.

\section{Notes}

1 CP (abbr.: Collected Papers of C.S. Peirce followed by volume and paragraph number) e.g. CP 2.205, refers to Collected Papers vol. 2 paragraph 205.

2 (Fjordback, Andersen, \& Hjørland, 2003; Friedman \& Thellefsen, 2011; Hjørland, 2002a, 2002b, 2003; Hjørland, Søndergård, \& Andersen, 2005; Thellefsen, 2010; Thellefsen, Thellefsen, \& Sørensen, 2011; Thellefsen, 2004; Thellefsen \& Villemoes, 2003).

3 At least in the philosophical sense, where knowledge is related to truth conditions.

4 Crestani and Ruthven 2005) analyses three epistemological views of the concept of information need, a structure view, an individual view and a communication view, the latter being based in neo-pragmatism, (Feinberg, 2008) argues that classifications de facto are purposeful and persuasive, not objective registrants of information, and thus are facilitators of communication. (Thellefsen, 2010) argues from a semeiotic view, that the interactive process of searching a database should be seen as an act of quasicommunication.

5 In principle we may argue that the communication taking place between an information system and a user is self-communication, the user being the sender of a query, however, the interface and the semantic structure represented by a KOS provides different kinds of affordances, and thus communicate guidance, possibilities and constraints to the user.

6 Anomalous state of knowledge.

7 [17] refer to (Nahl, 2010).

8 It is important to notice that cognition, according to Peirce's philosophy, is part of semeiosis; thus, all reasoning is sign processes and every thought is a sign (cf. CP 5.314). If reasoning is semeiosis and IS and 
IR depends on reasoning, if follows that these concepts are subsumed semeiosis.

9 "Critic" is Peirce's own term see e.g. (CP 2.205).

10 Is doubt much more that an emotional state for Peirce? If so in what does this consists this "much more." In this quotation Peirce explains doubt and belief very clearly: "Belief is not a momentary mode of consciousness; it is a habit of mind essentially enduring for some time, and mostly (at least) unconscious; and like other habits, it is (until it meets with some surprise that begins its dissolution) perfectly self-satisfied. Doubt is of an altogether contrary genus. It is not a habit, but the privation of a habit. Now a privation of a habit, in order to be anything at all, must be a condition of erratic activity that in some way must get superseded by a habit." ('What Pragmatism Is', CP 5.417). Doubt is caused by information, and information always cause emotions if perceived, consequently doubt is an emotional state in the mind.

11 We strongly object to the idea of anomalous state of knowledge. An information need in terms of doubt is not anomalous to knowledge in terms of belief. They are a conceptual pair that is co-dependent and coevolutionary. Belief without doubt is impossible. Doubt without belief is impossible-likewise knowledge without information is impossible, and information without knowledge is impossible, seen from a semeiotic viewpoint.

12 Matter in the sense that information is matter!

13 We acknowledge that the KOS is a construct conglomerated by a diversity of different agents, however to the user the system is the counterpart in the communication process.

\section{References}

Andersen, Jack. 2004. Analyzing the role of knowledge organization in scholarly communication: an inquiry into the intellectual foundation of knowledge organization. Ph.D. dissertation. Copenhagen: Royal School of Library and Information Science.

Bates, Marcia J. 2002. Toward an integrated model of information seeking and searching (keynote address, Fourth International Conference on Information Needs, Seeking and Use in Different Contexts, Lisbon, Portugal, September 11, 2002.) New review of information behaviour research 3: 1-15.

Belkin, Nicholas J., Oddy, Robert N., and Brooks, Helen M. 1982. ASK for information retrieval: Part I. Background and theory. Journal of documentation 38: 61-71.

Borlund, Pia, and Ingwersen, Peter. 1997. The development of a method for the evaluation of interactive in- formation retrieval systems. Journal of documentation 53: 225-50.

Brier, Søren. 2004. Cybersemiotics and the problems of the information-processing paradigm as a candidate for a unified science of information behind library information science. Library trends 52 no. 3: 629-57.

Brier, Søren. 2006a. Cybersemiotics: why information is not enough! A trans-disciplinary approach to information, cognition and communication studies, through an integration of Niklas Lubmann's communication theory with C. S. Peirce's semiotics. Ph.D. dissertation. CBS, Kbh.

Brier, Søren. 2006b. The foundation of LIS in information science and semiotics. Libreas 06 no. 1.

Brookes, Bertram C. 1975. The fundamental problem of information science. In Horsnell, Verina, ed. Informatics 2. London: Aslib, pp. 42-9.

Brookes, Bertram C. 1980a. The foundation of information science: Part 1: Philosophical aspects. Journal of information science 2: 125-33.

Brookes, Bertram C. 1980b. The foundations of information science: part I: philosophical aspects. Journal of information science 2: 125-33.

Broughton, Vanda, Hansson, Joacim, Hjørland, Birger and López-Huertas, María J. 2005. Knowledge organization. In Kajberg, Leif and Lorring, Leif, eds. European curriculum reflections on library and information science education. Royal School of Library and Information Science, Copenhagen, pp. 133-48.

Buckland, Michael K. 1991. Information and information systems. New York: Praeger.

Case, Donald O. 2007. Looking for information: A survey of research on information seeking, needs, and behaviour (2nd. ed.). Amsterdam: Academic Press.

Chowdhury, G.G., and Chowdhury, Sudatta. 2007. Organizing information: from the shelf to the web. London: Facet Publishing.

Crestani, Fabio, and Ruthven, Ian, eds. 2005. CoLIS 2005, Lecture notes in computer science volume 3507, 2005, pp. 107-18.

Dervin, Brenda. 1998. Sense-making theory and practice: an overview of user interests in knowledge seeking and use. Journal of knowledge management 2: 36-46.

Dervin, Brenda, and Nilan, Michael. 1986. Information needs and uses. Annual review of information science \& technology 21: 3-31.

Ellis, David. 1990. New borizons in information retrieval. London: The Library Association.

Feinberg, Melanie. 2008. Classification as communication: Properties and design. Ph.D. Dissertation. Washington: University of Washington. Available https://http:// www.ischool.utexas.edu/ feinberg/Feinbergdisserta tion.pdf 
M. Thellefsen, T. Thellefsen, B. Sørensen. A Pragmatic Semeiotic Perspective on the Concept of Information Need...

Fjordback, Trine, Andersen, Jack, and Hjørland, Birger. 2003. Documents and the communication of scientific and scholarly information: Revising and updating the UNISIST model. Journal of documentation 59: 278-320.

Forster, Paul. 2011. Peirce and the threat of nominalism. New York: Cambridge University Press.

Friedman, Alon., and Thellefsen, Martin. 2011. Concept theory and semiotics in knowledge organization. Journal of documentation 67: 644-74.

Frohmann, Bernd. 1992. The power of images: A discourse analysis of the cognitive viewpoint. Journal of documentation 48: 365-86.

Frohmann, Bernd. 2004. Documentation redux: prolegomenon to (another) philosophy of information. $\mathrm{Li}$ brary trends 52 no. 3: 387-407.

Göker, Ayse, and Davis, John. 2009. Information retrieval: Searching in the 21st century. West Sussex, UK: John Wiley \& Sons.

Hagler, Ronald. 1997. The Bibliographic record and information technology 3rd ed. Chicago: American Library Association.

Hjørland, Birger. 1997. Information seeking and subject representation. Westport, Conn.: Greenwood Press.

Hjørland, Birger. 2002a. Domain analysis in information science: eleven approaches-traditional as well as innovative. Journal of documentation 58: 422-62.

Hjørland, Birger. 2002b. Epistemology and the sociocognitive perspective in information science. Journal of the American Society for Information Science and Technology 53: 257-70.

Hjørland, Birger. 2003. Fundamentals of knowledge organization. Knowledge organization 30: 87-111.

Hjørland, Birger. 2008. What is knowledge organization? Knowledge organization 35: 86-101.

Hjørland, Birger, and Albrechtsen, Hanne. 1995. Toward a new horizon in information science: domainanalysis. Journal of the American Society for Information Science 46: 400-25.

Hjørland, Birger, Søndergård, Trine Fjordback, and Andersen, Jack. 2005. UNISIST model and knowledge domains. In Encyclopedia of library and information science. Boca Raton, FL: Taylor \& Francis, pp. 1-14.

Hodge, Gail. 2000. Systems of knowledge organization for digital libraries: beyond traditional authority files. Washington, DC: The Digital Library Federation.

Ingwersen, Peter. 1996. Cognitive perspectives of information retrieval interaction: Elements of a cognitive IR theory. Journal of documentation 52: 3-50.

Kuhlthau, Carol Collier. 1991. Inside the search process: Information seeking from the user's perspective. Journal of the American Society for Information Science 42: 361-71.

Kuhlthau, Carol Collier. 2004. Seeking meaning - a process approach to library and information services 2nd ed. Michigan: Libraries Unlimited.
Lykke Nielsen, Marianne. 2002. The word association method. Ph.D. dissertation. Åbo: Åbo Akademi University.

Nahl, Diane. 2010. User-centered revolution 1970-1995. In Bates, Marcia J., and Maack, Niles, eds. Encyclopedia of library and information science third edition. Boca Raton, FL: CRC Press , pp. 5461-95.

Peirce, Charles S. 1958-1966. Collected papers of Charles Sanders Peirce (Vol. I-VIII), ed. By Charles Hartshorne and Paul Weiss( vols. 1-6) and Arthur W. Burks (vols. 7-8). Cambridge, MA: Harvard University Press.

Peirce, Charles S. 1992. The essential Peirce: selected philosophical writings. Bloomington: Indiana University Press.

Rowley, Jennifer, \& Hartley, Richard. 2007. Organizing knowledge: an introduction to managing access to information Aldershot: Ashgate.

Sørensen, Bent, Thellefsen, Torkild, and Thellefsen, Martin. 2013. The meaning creation process, information, emotion, knowledge, two objects and the significanceeffects—-some Peircean remarks. Semiotica forthcoming.

Taylor, Robert S. 1968. Question-negotiation and information seeking in libraries. College and research libraries 29: 178-94.

Thellefsen, Torkild. 2004. Knowledge profiling: The basis for knowledge organization. Library trends 52 no. 3: 507-14.

Thellefsen, Martin. 2010. Knowledge organization, concepts, signs: A semeiotic framework. Ph.D. dissertation. Aalborg: Royal School of Library and Information Science.

Thellefsen, Torkild, Thellefsen, Martin, and Sørensen, Bent. 2013. Emotion, information and cognition and some possible consequences for library and information science. Journal of the American Society for Information Science and Technology 64: $\mathrm{xxx}-\mathrm{xxx}$.

Thellefsen, Martin, Thellefsen, Torkild, and Sørensen, Bent. 2011. The semiotic of knowledge organization: Profiling conceptual knowledge. In Thellefsen, Torkild, Sørensen, Bent, and Cobley, Paul, eds., From First to Third via Cybersemiotics: A festschrift honoring professor Soren Brier on the occation of his 60th birthday, Copenhague: SL Forelagene, pp. 395-422.

Thellefsen, Torkild, Sørensen, Bent, and Thellefsen, Martin. 2011. The significance-effect is a communicational effect: introducing the DynaCom. Sign Systems Studies 39: 209-22.

Thellefsen, Torkild, Sørensen, Bent, Thellefsen, Martin, and Andersen, Christian. 2006. Formal conditions for the significance-effect. Semiotica 158 no. 1-4: 401-6.

Thellefsen, Torkild, Brier, Søren, and Thellefsen, Martin. 2003. Problems concerning the process of subject analysis and the practice of indexing. Semiotica 144 no. 1-4: 177-218. 
Thellefsen, Torkild, and Villemoes, Lisbeth. 2003. Knowledge profiling the occupational therapy concept of activity. Ergoterapeuten: 1-14.
Wilson, Patrick. 1968. Two kinds of power: an essay on bibliographical control. Berkeley, CA: University of California Press. 